\title{
A Functional Modeling Approach to Stock Market Momentum
}

\author{
Qian Wei ${ }^{1}$, Xiang Gao ${ }^{2}$, Zhan Wang ${ }^{2}$ \\ ${ }^{1}$ Guangxi University of Foreign Languages, Nanning, China \\ ${ }^{2}$ Research Center of Finance, Shanghai Business School, Shanghai, China \\ Email: *zhanwang@sbs.edu.cn
}

How to cite this paper: Wei, Q., Gao, X., \& Wang, Z. (2021). A Functional Modeling Approach to Stock Market Momentum. Theoretical Economics Letters, 11, 871-880. https://doi.org/10.4236/tel.2021.115055

Received: August 2, 2021

Accepted: September 3, 2021

Published: September 6, 2021

Copyright $\odot 2021$ by author(s) and Scientific Research Publishing Inc. This work is licensed under the Creative Commons Attribution International License (CC BY 4.0).

http://creativecommons.org/licenses/by/4.0/

\begin{abstract}
This paper proposes a novel dynamic function to capture the phenomenon of momentum in financial markets. It occurs when high returns subsequently follow a security's past high returns, and subsequent low returns follow its past low returns. By exploring an analogy to the momentum definition from physics, we model financial momentum as the product of a stock's return and its number of shares outstanding with considerations of the difference between its market price and intrinsic price. In contrast to traditional proxies, where the momentum is described as the rate of acceleration of a security's price or volume and is calculated based on past 12-month returns or the associated accumulation in returns, the dynamics of our model exhibit advantageous trading characteristics for common momentum-based strategies.
\end{abstract}

\section{Keywords}

Momentum, Econophysics, Intrinsic Price, Return Prediction

\section{Introduction}

Momentum investors and contrarians consider asset pricing factors as capturing the pattern of an asset's return relative to its recent performance history. The common understanding of momentum (or contrarian) in the finance community is that stock market winners in the previous period tend to keep winning (become losers) in the sequent period. This line of research in the finance area begins with Noble Prize winner Richard Thaler. De Bondt \& Thaler $(1985,1987)$ build a contrarian investment strategy that investors earn a long-term abnormal return by holding stocks that have performed poorly in the previous three to five years. They demonstrate that the stock prices overreact to bad news because of 
retail investors' behavioral biases, and these prices will rebound to their reasonable levels over the long run. Jegadeesh (1990) and Lehmann (1990) find evidence that such reversal effect can also have influences even in a short sample period (i.e., around one month).

There also exist profitable strategies that stand on the opposite side of the contrarian approach. For example, Jegadeesh \& Titman (1993) develop a momentum trading strategy that buys the well-performed stocks and sells the poorly-performed shares and show that this strategy can produce a significant positive holding period return over the one-year holding period. After their seminal work, many studies investigate the momentum effects in various scenarios. For example, Asness (1994), Fama \& French (1998), Rouwenhorst (1998), Liew \& Vassalou (2000), Griffin, Ji, \& Martin (2003), and Chui, Titman, \& Wei (2010) report similar results as Jegadeesh \& Titman (1993). Regarding heterogeneity in location, Asness, Liew, \& Stevens (1996) and Bhojraj \& Swaminathan (2006) provide evidence of the momentum effects in other non-U.S. equity markets. In terms of alternative investment markets, Kho (1996) and LeBaron (1999) propose a method to measure the efficiency of the momentum strategy in currency markets. Erb \& Harvey (2006) and Gorton, Hayashi, \& Rouwenhorst (2012), on the other hand, confirm the existence of the momentum anomaly in commodity markets.

Given the above said, an important issue is how to define winners and losers. The previous literature suggests relying only on the holding period returns observed in the last investment period, i.e., stocks with relatively higher (lower) realized returns are categorized as winners (losers). However, this definition is to some extent vague as one can choose the benchmark arbitrarily. Our paper, hence, develops a new framework to explain the momentum and contrarian anomaly, attempting to propose a new measure so that the quantification of these effects is more accurate. To better understand our proposed structure, let us briefly introduce the original idea of momentum in the physical world. In physics, momentum is a tendency for an object with a certain mass to keep its current motion status. The magnitude of physical momentum equals the product of the mass and velocity of the object in Newtonian mechanics. As a result, an item with either a more significant mass or a higher speed, or both, will have a greater momentum level. Furthermore, an item's momentum will remain constant if there is no exogenous force. The momentum theory describes the mathematical relationship between the changes in momentum and the cumulative forces exerted in the system during a given time interval.

Turning back to the momentum and contrarian anomaly, in essence, they relate to the net "force" applied to securities within an investment period. For winners, if the driving force can still push their prices upward, winners keep their momentum. But if the driving force is too small to ensure their positive returns, winners experience a reversal. These forces include informed buying and selling orders, sentimental behaviors, and any imbalances in market activities. Although theo- 
retically so, in the real finance world, the drivers of security prices are too complex to identify or quantify. For this reason, all traditional approaches use the cumulative holding period return as an indicator of these unobservable forces.

\section{The Model}

In this section, we develop stock movement in the traditional physics framework and then formally apply the physical notion of momentum to financial markets.

\subsection{The Setup}

Think of any specific security as an object with a certain mass. Following this logic, a security's total share is analogous to the security's "mass" if the security is an object, which describes the scale of the security under concern. In addition, we match the price level of that security to the location of an object in the physical world; thus, the first derivative of the price level, namely the return, measures the "velocity" of the security when we treat it as an object in motion. Besides, the new information and associated trading activities can be re-described in the physical language as a process of exerting a force on security.

Without the arrival of new information, the market price of a security should move around its intrinsic value. Let the intrinsic value be a fixed nod; thus, the price movement of the security can be expressed as the movement of a mass that links to the fixed nod with an elastic rope. Because of the rope, the market price could not unlimitedly deviate from the intrinsic price and would eventually converge to the intrinsic price in the long term. Moreover, the driving force that brings the market price back to intrinsic price increases as the difference of these two prices increases, which is consistent with the physics theory. When new information arrives, the fixed nods may move to a new location, and the security price moves at a new level of velocity, which depends on the influence of the information (force) and the difference between market price and intrinsic price. This comparison between two distinct momentum definitions is summarized below (Table 1).

Table 1. A comparison of momentum in physics vs. finance.

\begin{tabular}{|c|c|c|}
\hline & Physics & Finance \\
\hline Definition of Momentum & $\begin{array}{l}\text { the product of the } \\
\text { mass and velocity }\end{array}$ & $\begin{array}{c}\text { the product of } \\
\text { the share } \\
\text { outstanding and return }\end{array}$ \\
\hline Parameters & Mass $(m)$; Velocity $(v)$ & $\begin{array}{c}\text { Share Outstanding }(N) \text {; } \\
\text { Security Return }(R)\end{array}$ \\
\hline Momentum Theorem & $\int_{t=0}^{T} F \mathrm{~d} t+m v$ & $\int_{t=0}^{T} F \mathrm{~d} t+N R$ \\
\hline The Meaning of Force $(F)$ & $\begin{array}{c}\text { The exogenous force applied } \\
\text { in the Newtonian system }\end{array}$ & $\begin{array}{c}\text { The driving force that makes } \\
\text { the market price of } \\
\text { the security converge } \\
\text { to its intrinsic price }\end{array}$ \\
\hline
\end{tabular}




\subsection{Analogy of Stock Momentum to Momentum from Physics}

In understanding the momentum anomaly of asset pricing, our momentum theorem derived from the above comparison table could play an essential role. Notice that the notation $F$ from the momentum theorem in physics is the exogenous force that is applied to an item. In the finance area, this force is analogous to the driving power that leads to the movement of security prices, including new information arrivals and associated trading activities based on new information. In short, $F$ should capture the momentum effect in finance terminology. However, it is a challenging task to quantify this force directly due to the complexity of forces that occurred in the financial market. To overcome the difficulty, we consider $F$ capturing the driving force that brings the market price back to its intrinsic price at a certain time point, which depends on the difference between market price and intrinsic price.

Then, we develop a new approach to measure the momentum effect in finance based on the momentum theorem during one investment period. Mathematically, the momentum effect in finance is expressed as below.

$$
\text { Momentum }=N R+\int_{t=0}^{T} \alpha\left(P^{*}-P\right) \mathrm{d} t,
$$

where $\alpha$ is a coefficient that measures the ratio of the driving force of the price difference. To normalize away the influence of the shares of a stock on its momentum, we divide Equation (1) by the number of shares outstanding.

$$
\text { Momentum }=R+\int_{t=0}^{T} \alpha\left(\frac{P^{*}-P}{N}\right) \mathrm{d} t .
$$

Equation (2) reveals that the momentum effect has three components. The first one is the holding period return of the previous period. The extant research all uses this component effect as an indicator of security momentum.

The second component is the percentage change in the company's number of shares outstanding. Consider a firm that issues new shares at the market price and finances its operation via extra cash from the issuance. The momentum of its stock will subsequently decrease as shown in Equation (2). In the short run, its stock price may decrease because additional issuance signals share dilution for existing investors. Nevertheless, in the long run, the company can make more profit since it has more working capital, and thus its stock can reach a higher market price. The opposite is true when the underlying firm repurchases shares. Based on the analysis, the firm's share price exhibits momentum effects in the short term and contrarian features in the long term.

The last component is the price difference between market price and intrinsic price, which has been largely ignored by the prior literature. Without the impact of new information, security's market price converges to its true value gradually. As a result, the securities with a lower current price compared to intrinsic price will have a higher chance to outperform, hence displaying the momentum effect. Conversely, the equity securities with the higher current price compared to the 
intrinsic price, although their cumulative returns may turn out to be positive, will have a larger probability of behaving according to the expectation of contrarians.

\section{Empirical Analysis of the Functionally Defined Momentum in Comparison to Traditional Momentum Measures}

In this section, we empirically analyze the return predictive power of our functionally defined momentum and compare it with the performance of the traditional momentum measures. We apply our theoretical framework to the U.S. equity markets. The monthly data from the CRSP equity database are employed here, and they cover all firms incorporated in the U.S. and listed on the NYSE, AMEX, or NASDAQ. The sample period covers from 1990 to 2019. To avoid the adverse effect of the survivorship bias and illiquidity issues on our estimates, we include only stocks traded for all 360 months. After data cleaning, our sample is composed of 919 firms and 330,840 observations.

Table 2 reports the summary statistics of the monthly returns of these CRSP stocks. We compute the average value of monthly return, market capitalization, price, and share outstanding of each stock, as well as the standard deviation of monthly return in the whole sample period, and then report the statistics of their distributions. In Table 2, the mean values and median values of the average return, standard deviation, and market size are very close, indicating that the distributions of return, standard deviation, and size of stocks all tend to be symmetric. Furthermore, the $5^{\text {th }}$ percentile and $95^{\text {th }}$ percentile values stay within rational boundaries, so these distributions are thin-tailed without significant outliers. The main reason is that our data cleaning procedure only keeps securities that have relatively stable return characteristics. Securities with unfavorable variations are excluded from the sample. Such treatment is in line with our goal of verifying the capability of our new quantification method in capturing momentum effects.

To investigate the return predictability of the momentum effect, we form a value-weighted quintile portfolio and rebalance it every month using return and market capitalization data from the previous month. Managers can employ the

Table 2. A comparison of momentum in physics vs. finance.

\begin{tabular}{cccccc}
\hline & $\begin{array}{c}\text { Average } \\
\text { Return }\end{array}$ & $\begin{array}{c}\text { Standard } \\
\text { Deviation }\end{array}$ & Size & Price & $\begin{array}{c}\text { Share } \\
\text { Outstanding }\end{array}$ \\
\hline Mean & 1.29 & 10.40 & 6.80 & 152.50 & 197,807 \\
Median & 1.20 & 9.33 & 6.76 & 29.49 & 46,842 \\
P5 & 0.59 & 4.60 & 3.50 & 6.20 & 4,271 \\
P25 & 0.94 & 7.11 & 5.34 & 16.65 & 15,343 \\
P75 & 1.54 & 12.66 & 8.24 & 44.61 & 150,103 \\
P95 & 2.31 & 19.62 & 10.16 & 74.93 & 741,020 \\
\hline
\end{tabular}

Note: All daily returns and standard deviations are non-annualized and reported in percentage. 
rebalancing rule to rank individual stocks based on their momentum.

We first consider the return component in momentum effect, which is also the well-accepted momentum indicator. In our analysis, individual stocks are sorted into ten groups according to their monthly returns; then we report the average returns of each group in the following one month, three months, six months, and twelve months. Table 3 summarizes the results. The row that is titled " $10-1$ " corresponds to the difference in post-monthly returns between the portfolios with the highest and lowest returns in the forming month. We report in square brackets the t-statistics. In Table 3, the average monthly returns following the forming month demonstrate an increasing pattern; that is, the higher the monthly return on the forming month, the larger the post returns. Especially for short period, the portfolios with the highest forming returns (rank 10) significantly outperform the portfolios with the lowest forming returns (rank 1). The results in Table 3 are consistent with the existing literature (Jegadeesh \& Titman, 1993; Fama \& French, 1998; Chui, Titman, \& Wei, 2010; etc.). The portfolio with a higher forming return earns higher post returns in the following months. The results are significant in short-term periods $(1$ month and 3 months), and become insignificant in the long run, indicating that the momentum effects have a short-run impact.

Now, we examine the effect of the second component of our momentum measure, which is our main contribution to the literature. Following the same procedure employed as in Table 3, we rank the individual stocks based on their $\left(P^{*}-P\right) / N$. We use the average price of the previous three months to proxy the

Table 3. The relations between previous and post monthly returns.

\begin{tabular}{cccccc}
\hline \multirow{2}{*}{ Rank } & \multirow{2}{*}{$\begin{array}{c}\text { Return of the } \\
\text { previous month }\end{array}$} & \multicolumn{4}{c}{ The Post Average Monthly Return } \\
\cline { 3 - 6 } 1 & -14.08 & 0.91 & 1.22 & 1.29 & 1.42 \\
2 & -6.59 & 0.91 & 1.07 & 1.09 & 1.2 \\
3 & -3.71 & 0.89 & 1.05 & 1.07 & 1.15 \\
4 & -1.70 & 1.03 & 1.08 & 1.08 & 1.14 \\
5 & -0.01 & 1.16 & 1.11 & 1.12 & 1.15 \\
6 & 1.61 & 1.15 & 1.17 & 1.14 & 1.14 \\
7 & 3.39 & 1.26 & 1.18 & 1.17 & 1.17 \\
8 & 5.59 & 1.39 & 1.24 & 1.24 & 1.2 \\
9 & 8.87 & 1.52 & 1.36 & 1.32 & 1.27 \\
10 & 19.30 & 1.91 & 1.6 & 1.52 & 1.48 \\
$10-1$ & & $1.00^{* * *}$ & $\mathbf{0 . 3 9 * * *}$ & $0.23^{* *}$ & 0.06 \\
& & {$[3.95]$} & {$[2.69]$} & {$[2.35]$} & {$[0.85]$} \\
\hline
\end{tabular}

Note: All monthly returns are non-annualized and reported in percentage. ${ }^{* *}$ means significance at the $1 \%$ level. ${ }^{\star *}$ means significance at the $5 \%$ level. 
intrinsic price $P^{*}$. Table 4 reports the results of the post returns. We observe the same pattern of monthly return as can be seen in Table 3 . The portfolios with a higher $\left(P^{*}-P\right) / N$ will generate significantly higher returns in the short term, indicating that $\left(P^{*}-P\right) / N$ is also an effective indicator of the momentum effect.

More importantly, the average correlation between $R$ and $\left(P^{*}-P\right) / N$ is around 0.01 ; thus the impacts of these two components can be considered as independent. As a result, our new momentum measure based on the co-impact of these two components does not have an endogeneity issue. Then we examine the joint effects of these two components on the post returns. Table 5 reports the post-three-month average returns of $R$ and $\left(P^{*}-P\right) / N$ double-sorted portfolios. We first divide the individual stocks equally into five groups according to their previous one-month returns. Next, for each group, we further sort group members into five subgroups based on the price difference. We use the three-month average return to investigate the momentum effect because the one-month results tend to be volatile.

In Table 5, the post returns increase significantly in both horizontal and vertical directions, while the average values and t-statistics are greater than the single-sorted results, indicating that our new approach, which considers both $R$ and $\left(P^{*}-P\right) / N$, reveals the momentum effect more efficiently.

At last, we form a momentum portfolio by longing the group with the largest previous return and price difference, while shorting the group with the smallest values of these two criteria, rebalancing every three months. Table 6 compares the performance of this momentum portfolio with the performance of two benchmark portfolios. The average monthly return of this momentum portfolio is $6.12 \%$, and the standard deviation is $4.27 \%$, resulting in the Sharpe ratio of 1.43 , which outperforms the portfolio that is singly sorted by previous return (i.e., the Sharpe ratio is 0.26), as well as the momentum portfolio in Kenneth French's Database (i.e., the Sharpe ratio is 0.11).

Table 4. The relations between $\left(P^{*}-P\right) / N$ and post monthly returns.

\begin{tabular}{cccccc}
\hline \multirow{2}{*}{ Rank } & $\left(P^{*}-P\right) / N$ & \multicolumn{4}{c}{ The Post Average Monthly Return } \\
\cline { 3 - 6 } & -4.84 & 1 month & 3 months & 6 months & 12 months \\
\hline 1 & -0.83 & 1.03 & 1.10 & 1.18 \\
2 & 0.17 & 0.77 & 0.99 & 1.05 & 1.19 \\
3 & -0.10 & 0.87 & 1.02 & 1.10 & 1.21 \\
4 & -0.05 & 1.02 & 1.14 & 1.17 & 1.24 \\
5 & -0.02 & 1.17 & 1.23 & 1.22 & 1.28 \\
6 & 0.01 & 1.36 & 1.27 & 1.26 & 1.27 \\
7 & 0.04 & 1.48 & 1.38 & 1.30 & 1.29 \\
8 & 0.07 & 1.52 & 1.35 & 1.28 & 1.25 \\
9 & 0.14 & 1.65 & 1.39 & 1.29 & 1.22 \\
10 & 3.42 & 1.44 & 1.24 & 1.21 & 1.15 \\
$10-1$ & & $0.61^{* * *}$ & $0.21^{* *}$ & 0.11 & -0.03 \\
& & {$[3.05]$} & {$[1.99]$} & {$[1.58]$} & {$[-0.74]$} \\
\hline
\end{tabular}

Note: All monthly returns are non-annualized and reported in percentage. ${ }^{* *}$ means significance at the $1 \%$ level. ${ }^{* *}$ means significance at the $5 \%$ level. 
Table 5. The relations among previous-one-month returns, $\left(P^{*}-P\right) / N$, and postthree-month average returns.

\begin{tabular}{|c|c|c|c|c|c|c|c|}
\hline \multirow{2}{*}{\multicolumn{2}{|c|}{$\begin{array}{l}\text { Previous } \\
\text { Returns }\end{array}$}} & 1 & 2 & 3 & 4 & 5 & \multirow{2}{*}{$5-1$} \\
\hline & & -10.06 & -2.69 & 0.80 & 4.48 & 13.69 & \\
\hline Rank & $\left(P^{*}-P\right) / N$ & & & & & & \\
\hline 1 & -1.22 & -1.55 & -1.44 & -1.22 & -1.13 & -0.93 & $\begin{array}{c}0.62^{* * *} \\
{[3.47]}\end{array}$ \\
\hline 2 & -0.04 & 0.90 & 0.35 & 0.24 & 0.09 & -0.17 & $\begin{array}{c}1.07^{* * *} \\
{[7.71]}\end{array}$ \\
\hline 3 & 0.00 & 1.73 & 1.20 & 1.00 & 0.84 & 0.78 & $\begin{array}{c}0.95^{* * *} \\
{[7.75]}\end{array}$ \\
\hline 4 & 0.04 & 2.33 & 2.12 & 2.07 & 1.90 & 1.83 & $\begin{array}{c}0.50^{* * *} \\
{[4.26]}\end{array}$ \\
\hline 5 & 1.26 & 3.33 & 3.54 & 3.65 & 3.93 & 4.95 & $\begin{array}{l}1.62^{* * *} \\
{[10.21]}\end{array}$ \\
\hline $5-1$ & & $\begin{array}{l}4.88^{* * *} \\
{[34.25]}\end{array}$ & $\begin{array}{l}4.97^{* * *} \\
{[49.60]}\end{array}$ & $\begin{array}{l}4.86^{* * *} \\
{[50.24]}\end{array}$ & $\begin{array}{l}5.06^{* * *} \\
{[46.82]}\end{array}$ & $\begin{array}{l}5.88^{* * *} \\
{[36.60]}\end{array}$ & \\
\hline
\end{tabular}

Note: All monthly returns are non-annualized and reported in percentage. ${ }^{* * *}$ indicates significance at $1 \%$ level.

Table 6. The performances of momentum portfolios of different approaches.

\begin{tabular}{cccc}
\hline & $\begin{array}{c}\text { Average } \\
\text { Return }\end{array}$ & $\begin{array}{c}\text { Standard } \\
\text { Deviation }\end{array}$ & $\begin{array}{c}\text { Sharpe } \\
\text { Ratio }\end{array}$ \\
\hline Return and price difference double-sorted portfolio & 6.12 & 4.27 & 1.43 \\
Return-sorted portfolio & 1.00 & 3.86 & 0.26 \\
Fama-French momentum portfolio & 0.50 & 4.73 & 0.11 \\
\hline
\end{tabular}

Note: All daily returns and standard deviations are non-annualized and reported in percentage.

\section{Conclusion and Further Research}

In this paper, we use the notation of momentum in the traditional physics field and develop a new approach to measure the momentum effects in the financial markets. In our theoretical framework, the price movement of an equity security is influenced by not only its previous returns but also the price deviation from its intrinsic value. For our empirical results, the securities with higher previous returns or higher price deviation generate significantly higher post returns in the short run, which is consistent with the notation of momentum effect in the finance field.

The limitation of this study is twofold. First, it is difficult to appropriately estimate the intrinsic price; thus the proxy that we propose for measuring the price difference may be biased. Second, our approach only focuses on the informa- 
tional content of transactions and may ignore the information contained in company fundamentals. As a result, the industry analysis and other analyses based on corporate information can be executed along with our method to further understand the properties of momentum effects.

\section{Conflicts of Interest}

The authors declare no conflicts of interest regarding the publication of this paper.

\section{References}

Asness, C. (1994). Variables That Explain Stock Returns. Ph.D. Thesis, University of Chicago.

Asness, C., Liew, J., \& Stevens, R. (1996). Parallels between the Cross-Sectional Predictability of Stock and Country Returns. SSRN Working Paper.

https://ssrn.com/abstract $=7482$

Bhojraj, S., \& Swaminathan, B. (2006). Macromomentum: Returns Predictability in International Equity Indices. The Journal of Business, 79, 429-451.

https://doi.org/10.1086/497416

Chui, A., Titman, S., \& Wei, K. (2010). Individualism and Momentum around the World. The Journal of Finance, 65, 361-392. https://doi.org/10.1111/j.1540-6261.2009.01532.x

De Bondt, W., \& Thaler, R. (1985). Does the Stock Market Overreact? The Journal of Finance, 40, 793-805. https://doi.org/10.1111/j.1540-6261.1985.tb05004.x

De Bondt, W., \& Thaler, R. (1987). Further Evidence on Investor Overreaction and Stock Market Seasonality. The Journal of Finance, 42, 557-581. https://doi.org/10.1111/j.1540-6261.1987.tb04569.x

Erb, C., \& Harvey, C. (2006). The Strategic and Tactical Value of Commodity Futures. Financial Analysts Journal, 62, 69-97. https://doi.org/10.2469/faj.v62.n2.4084

Fama, E., \& French, K. (1998). Value versus Growth: The International Evidence. The Journal of Finance, 53, 1975-1999. https://doi.org/10.1111/0022-1082.00080

Gorton, G., Hayashi, F., \& Rouwenhorst, K. (2012). The Fundamentals of Commodity Futures Returns. Yale ICF Working Paper No. 07-08. https://ssrn.com/abstract=996930

Griffin, J., Ji, X., \& Martin, J. (2003). Momentum Investing and Business Cycle Risk: Evidence from Pole to Pole. The Journal of Finance, 58, 2515-2547. https://doi.org/10.1046/j.1540-6261.2003.00614.x

Jegadeesh, N., \& Titman, S. (1993). Returns to Buying Winners and Selling Losers: Implications for Stock Market Efficiency. The Journal of Finance, 48, 65-91. https://doi.org/10.1111/j.1540-6261.1993.tb04702.x

Jegadeesh, N. (1990). Evidence of Predictable Behavior of Security Returns. The Journal of Finance, 45, 881-898. https://doi.org/10.1111/j.1540-6261.1990.tb05110.x

Kho, B. (1996). Time-Varying Risk Premia, Volatility, and Technical Trading Rule Profits: Evidence from Foreign Currency Futures Markets. Journal of Financial Economics, 41, 249-290. https://doi.org/10.1016/0304-405X(95)00861-8

LeBaron, B. (1999). Technical Trading Rule Profitability and Foreign Exchange Intervention. Journal of International Economics, 49, 125-143.

https://doi.org/10.1016/S0022-1996(98)00061-0

Lehmann, B. (1990). Fads, Martingales, and Market Efficiency. Quarterly Journal of Eco- 
nomics, 105, 1-28. https://doi.org/10.2307/2937816

Liew, J., \& Maria V. (2000). Can Book-to-Market, Size, and Momentum Be Risk Factors that Predict Economic Growth? Journal of Financial Economics, 57, 221-245. https://doi.org/10.1016/S0304-405X(00)00056-8

Rouwenhorst, K. G. (1998). International Momentum Strategies. The Journal of Finance, 53, 267-284. https://doi.org/10.1111/0022-1082.95722 